Discussion

Papers

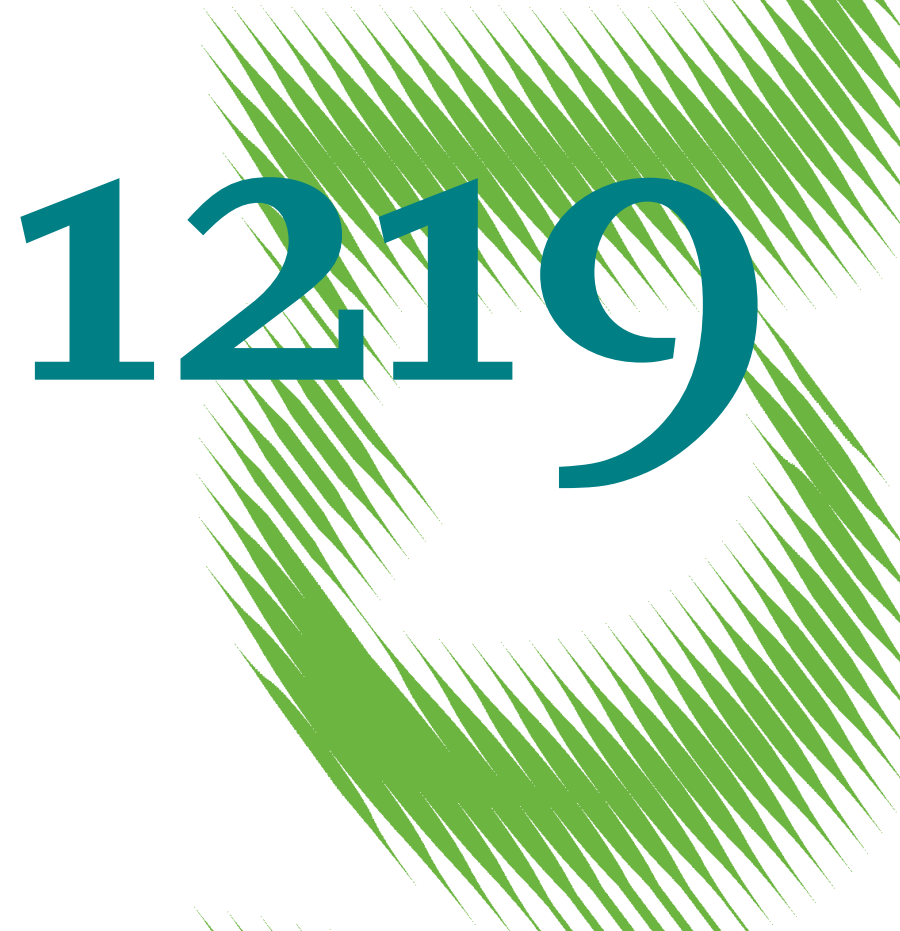

German Nuclear Phase-out Policy

Effects on European Electricity Wholesale Prices, Emission Prices, Conventional Power Plant Investments and Electricity Trade 
Opinions expressed in this paper are those of the author(s) and do not necessarily reflect views of the institute.

IMPRESSUM

(C) DIW Berlin, 2012

DIW Berlin

German Institute for Economic Research

Mohrenstr. 58

10117 Berlin

Tel. $+49(30) 89789-0$

Fax +49 (30) $89789-200$

http://www.diw.de

ISSN print edition $1433-0210$

ISSN electronic edition 1619-4535

Papers can be downloaded free of charge from the DIW Berlin website:

http://www.diw.de/discussionpapers

Discussion Papers of DIW Berlin are indexed in RePEc and SSRN:

http://ideas.repec.org/s/diw/diwwpp.html

http://www.ssrn.com/link/DIW-Berlin-German-Inst-Econ-Res.html 


\title{
German Nuclear Phase-out Policy - Effects on European Electricity Wholesale Prices, Emission Prices, Conventional Power Plant Investments and Electricity Trade ${ }^{1}$
}

\author{
Thure Traber ${ }^{2}$ and Claudia Kemfert
}

\begin{abstract}
The German decision to finally phase-out nuclear electricity has led to a debate on its effects on electricity prices, emission prices in the European emission trading system, as well as on international electricity trade. We investigate these effects with a Electricity market model for Europe with investments in power plants under oligopolistic conditions in Germany. We find modest price increases on the German wholesale market by the mid-term 2020 and an effect of the accelerated nuclear phaseout of between four and twelve percent. Moreover, the increase in the emission allowance prices due to the change in nuclear policy is between 1.8 and 3 Euro per ton of $\mathrm{CO}_{2}$ by the same period. The large variations in our results are induced by four combinations of the European emission trading policy and the success of the German energy efficiency policy. Most pronounced price effects are found in scenarios with a successful energy savings policy, which acts as a substitute for new power plants. Moreover, the tighter the emission trading system is, the larger are the effects of the accelerated phase-out on electricity and emission prices. Under a tight system, however, investments in conventional generation are likely to be dominated by natural gas fired plants since the decrease of utilization rates induced by renewable energies are more important for coal fired power plants with their relative high investment costs.
\end{abstract}

JEL classification: C63, L13, L94, Q38,

Keywords: energy modeling; nuclear phase-out; climate policy; oligopoly;

\section{Introduction}

The German decision to phase-out nuclear electricity by the year 2023 has led to a debate on its effect on electricity prices, emission prices, and on international electricity trade. A plenty of studies have investigated phase-out effects on the German electricity system or electricity market which can be subdivided into studies that have been conducted to analyze the phase-out plan of the red-green government in the late nineties, and into studies that have been conducted in the aftermath of the Fukushima nuclear accident and the following decisions by the then black-yellow government in Germany. The latter studies are of far greater relevance, since the pace of the built up of renewable energy technologies and the according plans for the future have been expected only by a few observers, and, therfore have not been

\footnotetext{
${ }^{1}$ Financial support by the Mercator foundation is gratefully acknowledged.

${ }^{2}$ Corresponding author, German Institute for Economic Research (DIW Berlin), Mohrenstr. 58, D-10117 Berlin, Germany; Email: ttraber@diw.de, Tel.: +49-30-89789409, Fax: +49-30-89789113.
} 
accounted for earlier. Also the development of the European emission trading with very low emission prices has not been foreseen.

With regard to electricity prices, emission allowance prices and international electricity exchange the latest work either focuses predominantly on empirical evidence that was experienced after the German moratorium for 7 reactors in March 2012 (Matthes 2011a and b), or the simulation of the phase-out with numerical models for the analysis of future impacts (Kunz et al. (2011)).

The work of Matthes et al. (2011a) finds that the decision on the moratorium has increased the German electricity wholesale future prices after the announcement by about 1 cent per kWh, which was partially offset by subsequent price reductions. In a further paper (Matthes et al. 2011b) the authors find an impact of the Moratorium on the European emission allowance prices of about 2 euro per ton $\mathrm{CO}_{2}$. They moreover conclude that it is highly likely that the reduction of German nuclear electricity production has been compensated by French and Czech thermal units and reduced exports, while nuclear production increases of these countries are not possible.

Kunz et al. (2011) model the impacts of the moratorium and a complete nuclear phase-out until 2017 against a status quo scenario in a techno-economic cost minimization framework with a detailed network representation of the German and the central European network. Results are reported for a representative winter week. They find a electricity price increase in off peak hours between $0,5-2,5$ cent per $\mathrm{kWh}$ for moratorium and complete phase-out respectively. Moreover, the emission effect of a complete phase-out is calculated as 14.7 percent increase against the status quo. They claim that generation reduction induced by the moratorium can be compensated by reduced German net exports and higher utilization of fossil fired units. Second, they find a need for new installed capacity in either networks or power plants or both for the case of a complete phase-out until 2017, which is likely to be fulfilled mainly by the realisation of renewable energy investments and fossil power plant projects already scheduled. However, new investments are not calculated and effects induced by higher prices of emission allowances in the European emission trading system are not accounted for.

Similar price effects of a nuclear phase-out are found by Füsch et al. (2012) who apply a European electricity system model for long-term market projection. They find an electricity price effect between 0.4 and 0.9 cent per $\mathrm{kWh}$ in 2030 induced by a complete phase-out in comparision to the German nuclear prolongation envisaged by the end of 2010. However, the reported price effects have to be treated with caution. In the study electricity demand is assumed to be completely inelastic and effects on the emission market are not modelled endogenuosly.

To investigate major effects of the German accelerated nuclear-phase out, we develop a dynamic long term Cournot-Nash equilibrium model of the electricity sector of the European Union with market based supply and investment decisions under the presence of an emission trading system. There is a long tradition in applying Cournot models to the short to medium term analysis of electricity markets. Green and Newberry (1992), Bushnell et al. (2008), Neuhoff et al. (2005) provide 
prominent examples. Long term electricity market models that include investment decisions are also frequently used, but less straightforward in their development and interpretation compared to static approaches.

For instance, if the time structure of decisions is sequential and players investment decisions alter the investment decisions of other players as in the closed loop game structure investigated in Murphy and Smeers (2005), uniqueness of equilibria cannot be guaranteed for asymmetric players even in duopoly games. In our discrete multi period oligopoly application we furthermore regard intertemporal technology restrictions and costs of the ramp up of power plants, which itself is computational demanding. To ease computational burden, we use a decision structure where market power induces Nash equilibria in supplied quantities of firms that focus on these equilibria in their investment decision over a finite time horizon. The games structure can be termed open loop as another version of the Cournot duopoly of Murphy and Smeers (2005), which corresponds to a decision structure where current investment choices are linked to forward electricity sales. This is considered a reasonable good aproximation of the European situation where only a small share of electricity trade is carried out on spot markets.

\section{Model}

The model is formulated as two seperarte problems. One for the representation of electricity suppliers and another for simulation of international electricity traders. We first introduce the model for electricity supply, where it is assumed that each firm supplies to a domestic market and regional indeces can be suppressed ${ }^{3}$.

The profit maximization problem with regard to production $q$, ramping $r$, and investment $k$ of firm $i$ is written as

$$
\max _{q, r, k} \pi^{i}=\sum_{y=1}^{Y} \sum_{t=1}^{T} \sum_{n=1}^{N}\left(P^{y, t}\left(X^{y, t}\right) q^{i, y, t, n}-C_{q}^{n} q^{i, y, t, n}-C_{r}^{n} r^{i, y, t, n}-F^{n} k^{i, y, n}\right)\left(\frac{1}{1+\delta}\right)^{y}
$$

where inverse demand is denoted by $P^{y, t}\left(X^{y, t}\right)$. The formulation in (1) says that profits are simply the difference between discounted revenues and discounted costs of all periods $y$, time steps $t$, and all technologies $n$. Costs include payments for emission allowances and are seperated into variable production with constant costs $C_{q}^{n}$, ramping with constant $\operatorname{costs} C_{r}^{n}$, and investment with constant costs $F^{n}$.

Variable production can also be expressed as

$$
C_{q}^{n}=\frac{p^{n}+\sigma e^{n}}{\eta^{n}}+o c^{n}
$$

\footnotetext{
${ }^{3}$ For a model where oligopolistic firms may supply also to foreign markets see Traber and Kemfert (2011). The full model notation is summarized at the end of the paper.
} 
where $\sigma$ denotes the emissions price, and $p^{n}, e^{n}, \eta^{n}$ and $o c^{n}$ denote the fuel price, the fuel emission, the degree of efficiency, and the variable operation and maintenance costs of technology $n$ respectively.

Furthermore, we decompose the ramping costs into the ramping fuel requirement, $r f^{n}$, and increased depreciation due to ramping, $d^{n}$, as follows:

$$
C_{r}^{n}=r f^{n}\left(p^{n}+\sigma e^{n}\right)+d^{n}
$$

The choice of the decision variables is furthermore bound by the following restrictions. The first restriction ensures that production cannot exceed the maximum of available installed net generation capacity:

$$
\bar{q}^{i, y, n} \geq q^{i, y, t, n} .
$$

The according net installed generation capacity is determined by $\bar{q}^{i, y, n}=\bar{q}_{0}^{i, y, n}+$ $\sum_{z=1}^{y-1} k^{i, z, n}$ i.e. consisting of remaining base year capacity $\bar{q}_{0}^{i, y, n}$ and the sum of newly installed capacity commissioned until the period under consideration.

The second restriction excludes a ramp-up greater than the feasible technical maximum, which is the product of the maximum ramp-rate $\bar{r}^{n}$ and the installed available capacity $\bar{q}^{i, y, n}$ :

$$
\bar{r}^{n} \bar{q}^{i, y, n} \geq r^{i, y, t, n} .
$$

A third condition demands that the increase of generation between two time steps cannot exceed the according ramp-up:

$$
r^{i, y, t, n} \geq q^{i, y, t, n}-q^{i, y, t-1, n} .
$$

A fourth restriction ensures that new installation does not exceed any geographic or political restrictions for the expansion of certain technologies ${ }^{4} \bar{k}^{i, y, n}$, and writes

$$
\bar{k}^{i, y, n} \geq k^{i, y, n} .
$$

We now introduce the linkage between the modelled regions. Therefore a regional index has to be added. More precisely, exports of electricity from region $s$ to region $s s$ is guided by the following profit maximization problem of a representative arbitrageur $a$ :

$$
\max _{E x} \pi^{a}=\sum_{y=1}^{Y} \sum_{t=1}^{T}\left(P^{y, t, s s}\left(X^{y, t, s s}\right) E x^{y, t, s, s s}-P^{y, t, s}\left(X^{y, t, s}\right) E x^{y, t, s, s s},\right.
$$

where $E x^{y, t, s, s s}$ denotes electricity exports from country $s$ to the country of destina-

\footnotetext{
${ }^{4}$ For instance, the possible expansion of gas fired power plants in Poland is limited by political objections against a further increase of the dependency on Russian gas. Also, coal fired power plants are not economic viable in certain countries, e.g. Switzerland, due to the absence of an own resource base and the lack of suitable ports.
} 
tion ss. Clearly, exports are restricted to the maximum transmission line capacity $\overline{E x}$ such that

$$
\overline{E x}^{y, s, s s} \geq E x^{y, t, s, s s} .
$$

The model is completed by equalities related to market clearing.

Market clearing ensures the following symmetry of electricity supply and isoelastic demand with elasticity $\epsilon$, reference demand $D 0$, and reference price $P 0$,

$$
X^{y, t}=D 0^{y, t}\left(\frac{P^{y, t}}{P 0^{y, t}}\right)^{\epsilon}
$$

where $X^{y, t}=Q^{y, t}+R E S^{y, t}+I m^{y, t}-E x^{y, t}$ sums up conventional supply $Q^{y, t}$, renewable energy generation $R E S$, and imports from neighbouring markets $I m$ net of exports Ex. Furthermore, market clearing on the emission market is achieved by the equivalence of the periodic emission cap $\bar{E}^{y}$ and the sum of periodic emissions of all firms $E^{y}$ and requires:

$$
\bar{E}^{y}=E^{y} .
$$

The two basic problems are furthermore formulated as Mixed Complementarity Problems for the implementation in $\mathrm{GAMS}^{5}$.

The problem of the generating firm (1) can be stated as the following Lagrangian of the Karush-Kuhn-Tucker type.

$$
\begin{aligned}
\max _{q, r, k} L^{i}= & \sum_{y=1}^{Y} \sum_{t=1}^{T} \sum_{n=1}^{N}\left(P^{y, t}\left(X^{y, t}\right) q^{i, y, t, n}-C_{q}^{n} q^{i, y, t, n}-C_{r}^{n} r^{i, y, t, n}-F^{n} k^{i, y, n}\right. \\
& -\kappa^{i, y, t, n}\left(q^{i, y, t, n}-\bar{q}^{i, y, n}\right) \\
& -\rho^{i, y, t, n}\left(r^{i, y, t, n}-\bar{r}^{i, n} \bar{q}^{i, y, n}\right) \\
& -\psi^{i, y, t, n}\left(q^{i, y, t, n}-q^{i, y, t-1, n}-r^{i, y, t, n}\right) \\
& \left.-\iota^{i, y, n}\left(k^{i, y, n}-\bar{k}^{i, y, n}\right)\right)\left(\frac{1}{1+\delta}\right)^{y}
\end{aligned}
$$

with $\kappa$ denoting the shadow price of available capacity, $\rho$ the shadow price of the ramp-up restriction, $\psi$ the shadow price of the ramp-up requirement, and $\iota$ the shadow price of the investment restriction.

Taking the derivatives of the Lagrangian (12) yields the first order conditions that are used for the numerical calculation of the model. First, in case of a price taking firm without market power, optimality with respect to the supplied quantity is ruled by

$$
\frac{\partial L^{i}}{\partial q^{i, y, t, n}}=P^{y, t}-C_{q}^{n}-\kappa^{i, y, t, n}-\psi^{i, y, t, n}+\psi^{i, y, t+1, n} \leq 0 .
$$

\footnotetext{
${ }^{5}$ General Algebraic Modeling System.
} 
In regard to the ramping decision the following optimality condition is central

$$
\frac{\partial L^{i}}{\partial r^{i, y, t, n}}=\psi^{i, y, t, n}-C_{r}^{n}-\rho^{i, y, t, n} \leq 0 .
$$

Investment decisions are guided by

$$
\frac{\partial L^{i}}{\partial k^{i, y, n}}=\sum_{z=y}^{Y} \sum_{t=1}^{t}\left(\left(\kappa^{i, z, t, n}+\rho^{i, z, t, n} \bar{r}^{i, n}-\iota^{i, y, n}\right)\left(\frac{1}{1+\delta}\right)^{y}\right)-F^{n} \leq 0 .
$$

Moreover, for a optimum the following non-negativity and complementarity conditions have to hold: $q^{i, y, t, n} \geq 0, \frac{\partial L^{i}}{\partial q^{i, y, t, n}} q^{i, y, t, n}=0, r^{i, y, t, n} \geq 0, \frac{\partial L^{i}}{\partial r^{i, y, t, n}} r^{i, y, t, n}=0$, $k^{i, y, n} \geq 0$, and $\frac{\partial L^{i}}{\partial k^{i, y, n}} k^{i, y, n}=0$. Consequently, in cases where the decision variables are greater than zero, the conditions (13)-(15) hold with equality and can be interpreted as follows.

If generation is positive, the market prices in (13) exactly match the sum of variable generation costs, shadow price of the capacity constraint and shadow price of the ramp-up requirement net of the shadow price of the ramping requirement in the succesive time step. In case of a positive ramp-up, (14) distinguishes two situations, where the ramp-up restrinction is either binding or not. If the ramp-up restriction is not binding, the shadow price of the ramping requirement equals simply the unit ramp-up costs. Otherwise, the shadow price of the ramping restriction is added to ramp-up costs. Furthermore, if ramp-up in two succeeding time steps is positive and in both time steps the ramping restriction is not exhausted, ramping is not considered in the output decision. To the contrary, the costs of ramping are fully assigned to those periods of ramping that are followed by periods without ramp-up.

Moreover, for a positive investment it is neccessary that unit investment costs equals at least the sum of discounted revenues from the investment in succeeding periods. If the investment restriction is not exhausted, these revenues are the sum of shadow prices of the capacity restrictions and shadow prices of the ramping requirement weighted with the maximum ramp-up rate. Exhaustion of the investment restriction allows for situations where these revenues exceed the investment costs by the sum of discounted shadow prices of the investment restriction.

If firms are aware of their market power, they choose quantities according to a Nash-Cournot behaviour. In equilibrium, for a firm with market power and market share $\vartheta(13)$ becomes

$$
\frac{\partial L^{i}}{\partial q^{i, y, t, n}}=P^{y, t}\left(1-\frac{\vartheta^{i, y, t}}{\epsilon}\right)-C_{q}^{n}-\kappa^{i, y, t, n}-\psi^{i, y, t, n}+\psi^{i, y, t+1, n} \leq 0 .
$$

The remaining first order conditions are not affected by the change of the behavioral assumption. This means that we do not account for strategic investment behavior in which firms might try to influence each others investment decisions by their own investments. The game structure therefore falls into the class of open loop equilibrium games with reduced conditions for uniqueness compared to closed loop 
games, which take a sequential game structure into account (Murphy and Smeers 2008).

Proceeding with the decision of arbitrageurs to trade electricity in a similar fashion, we set up the following Lagrangian with $\tau^{s, s s}$ denoting the shadow price of the transmission capacity from country $s$ to country ss:

$L^{a}=\sum_{y=1}^{Y} \sum_{t=1}^{T}\left(P^{y, t, s s}\left(X^{y, t, s s}\right) E x^{y, t, s, s s}-P^{y, t, s}\left(X^{y, t, s}\right) E x^{y, t, s, s s}-\tau^{s, s s}\left(E x^{y, t, s, s s}-\overline{E x}^{y, s, s s}\right)\right.$.

The respective first order condition for exports writes

$$
\frac{\partial L}{\partial E x^{y, t, s, s s}}=P^{y, t, s s}-P^{y, t, s}-\tau^{s, s s} \leq 0,
$$

and says that the prices of the import country have to cover prices of the export country plus the scarcity price of transmission capacity. Clearly, the above inequalities (13)-(16) and (18) have to hold for all periods $y$, time steps $t$, technologies $n$ and regions $s$.

\section{Scenarios and Data}

Calculation of the electricity price and emission price effects of the German accelerated phase-out requires a definition of the nuclear power prospects before the phase out decision. These are laid out in the nuclear energy act as of end 2010 (Atomgesetz (2010)). In comparision to the current plans defined in Atomgesetz (2011), in essence the phase-out of nuclear energy in Germany is brought forward from the year 2035 to the year 2023. Assuming a relative modest utilization of nuclear plant generation capacity of 81 percent ammounts in an average anual generation reduction of $71 \mathrm{TWh}$ in the years until 2035. In the following these two nuclear energy settings will be compared in scenarios for the development of the European emission trading reduction targets and the success of German energy efficiency policy and their combination. We use four scenarios:

- ETS- Effi+ combines the current ETS-regime with a successful energy efficiency policy,

- ETS- Effi- combines the current ETS-regime with a not successful energy efficiency policy,

- ETS+ Effi + combines a more ambitious ETS-regime with a successful energy efficiency policy,

- ETS- Effi- combines a more ambitious ETS-regime with a not successful energy efficiency policy. 
The current ETS-regime is assumed to reach a reduction of electricity sector emissions from 1264 Mio. tons in the year 2010 to 1000 and 736 Mio. tons in the years 2020 and 2030 respectively. By contrast, for the more ambitious ETS-regime a reduction to 900 and 550 Mio. tons by 2020 and 2030 is assumed. Finally, the successful energy efficiency policy scenarios assume a zero increase of German electricity demand at base year 2010 prices, while a not succesful energy efficiency policy is represented by a 10 percent increase of demand from period to period.

A periodic 10 percent increase of electricity demand is also assumed for the other old member states, while for new member states a higher increase of electricity demand of 20 percent at reference prices is used. More into details, demand for Germany and the other 25 European countries, which are represented by 10 aggregates, is represented by isoelastic demand functions with reference quantities taken from ENTSOE ${ }^{6}$. Reference prices stem from several European energy exchanges ${ }^{7}$. All demand and price data is averaged to represent 48 hours of a typical day in the winter half year and a typical day in the summer half year.

Alongside demand and emission trading system developments, the roll-out of renewable energy electricity supply (RES-E), and the decommissioning and new installation of conventional power plant units are decisive drivers of the electricity market prospects. The countries of the European Union have laid out plans for the fulfillment of their renewable energy targets and the role of electricity in these plans (ECN 2011). According to these plans, the increase of installed capacity will be about 100 percent for biomass, 150 percent for wind and 250 percent for solar power plants relative to their values in 2010. The respective number for the comparatively far developed hydro resources are planned to increase by 12 percent. Furthermore, we include a net installation of RES-E capacity that keeps the same pace of development in absolute terms in the third decade of the century until 2030. In addition, the conventional power plant fleet, - mainly nuclear, coal, natural gas and oil fired units -, develops on the one hand in line with technical lifetime expectation of existing plants and, on the other hand, due to new commissioning of capacity. Those plants that are already under construction are considered exogenous given units, while plans for new capacity are tested for profitability by the model and only profitable plans are realized. The exogenously given capacity development from 2020 to 2030 is summarized by the figure 3. of the appendix, which shows that most model regions will see an increase of installed capacities due to the RES-E built up even without additional new projects. Only the nordic market and the polishczech aggregate is expected to experience a decrease in capacity without additional construction.

Natural gas and hard coal power plant investments are investigated endogenously. Their investment costs are 700 and 1300 per kW net electric capacity. Furthermore,

\footnotetext{
${ }^{6}$ In Germany the ENTSOE-statistics do not account for industrial and railway consumption in these at least partially seperated grids. Therefore, the ENTSOE demand of 488 TWh has been scaled up to match 530 TWh consumption reported in BDEW (2011).

${ }^{7}$ Austria and Germany: Phelix European Energy Exchange, Nordic and Baltic countries: Nordpool,Poland and Czech Republich: Polish Power Exchange (exchange rate 4.2 Zloty per euro), Switzerland SWISSIX (EEX), for the remaining countries Phelix EEX is used.
} 


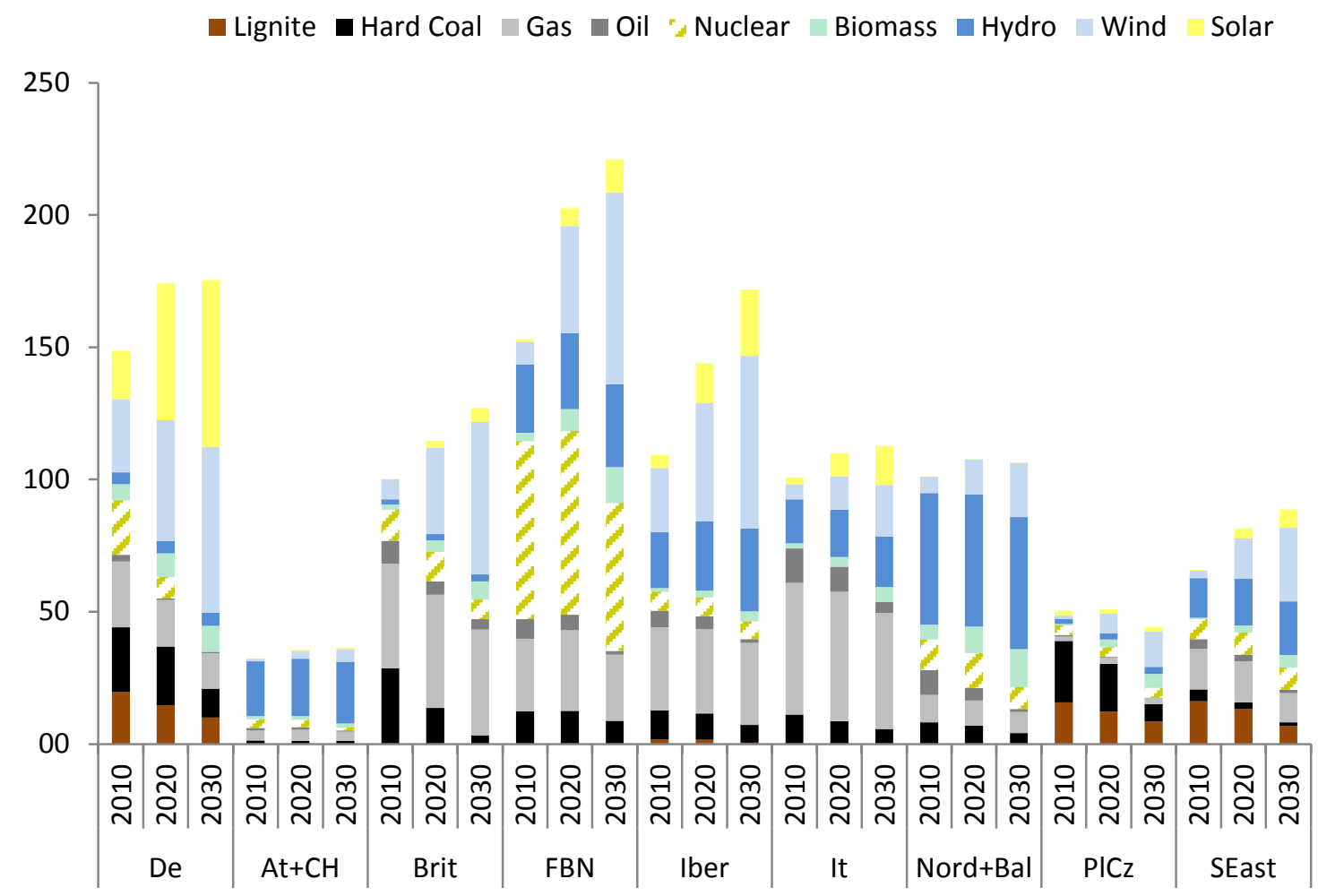

Figure 1: Exogenuous power plants in GW net capacity by 2020 and 2030 .

a discount rate of six percent per year for power plant investments is assumed. Our fuel price developments follow IEA (2012) projections, while 0,3 cent per $\mathrm{kWh}$ transport costs for hard coal are added.

The remaining assumptions in regard to the technologies are documented in Traber and Kemfert (2011). For this application we furthermore assume market power of the major German producers RWE, E.on, Vattenfall and EnBW. Finally, an elasticity of -0.3 has been found to replicate base year values fairly well and is assumed to be constant for all time steps, markets, and periods.

\section{Results}

In the following section we present and interprete results for average annual electricity wholesale prices in the modeled regions in the year 2020, the development of German electricity sector emissions, the prices in the emission trading system, and the investments in conventional power plants in the different scenarios and derive the effect of the accelerated German nuclear phase out. These findings are then complemented by the effects on international electricity trade. 
With a focus on price projections Table 1 reports $^{8}$ the modeled average electricity prices by 2020 in the regions, where the bloc on the right hand side refers to the effects induced by the nuclear phase out policy. For Germany we find electricity prices in 2020 between 5.1 and 6 Eurocent per $\mathrm{kWh}$ under the current nuclear energy policy, i.e. only about 15 percent higher than 2010 average prices despite significant natural gas price increases. Thereof between 0.2 and 0.6 Eurocent per $\mathrm{kWh}$ or between 4 and 10 percent can be attributed to the phase-out. Not surprisingly, in the scenario with high energy efficiency and an unambitiuos ETS target electricity prices are lowest, while a less successful energy efficiency policy combined with a more ambitious ETS regime leads to the highest prices. By contrast, the effect attributable to the phase-out is - even in absolute terms - the highest in cases of high energy efficiency. These findings have to be explained with the price dampening investment effects of the phase-out, which are larger in cases of low energy efficiency and are documented in detail below (Table 3).

\begin{tabular}{|c|c|c|c|c|c|c|c|c|c|c|c|c|}
\hline & \multicolumn{4}{|c|}{ Phase-out } & \multicolumn{4}{|c|}{ Extension } & \multicolumn{4}{|c|}{ Effect of Phase-out } \\
\hline & \multicolumn{2}{|c|}{ ETS- } & \multicolumn{2}{|c|}{ ETS+ } & \multicolumn{2}{|c|}{ ETS- } & \multicolumn{2}{|c|}{ ETS+ } & \multicolumn{2}{|c|}{ ETS- } & \multicolumn{2}{|c|}{ ETS+ } \\
\hline & Effi+ & Effi- & Effi+ & Effi- & Effi+ & Effi- & Effi+ & Effi- & Effi+ & Effi- & Effit & Effi- \\
\hline$\overline{\mathrm{De}}$ & 5.1 & 5.3 & 5.6 & 6.0 & 4.6 & 5.1 & 5.0 & 5.7 & 0.5 & 0.2 & 0.6 & 0.4 \\
\hline At & 5.1 & 5.3 & 5.6 & 6.0 & 4.6 & 5.1 & 5.0 & 5.7 & 0.5 & 0.2 & 0.6 & 0.3 \\
\hline $\mathrm{CH}$ & 5.1 & 5.3 & 5.6 & 6.0 & 4.6 & 5.1 & 5.0 & 5.7 & 0.5 & 0.2 & 0.6 & 0.4 \\
\hline Bal & 6.0 & 6.1 & 6.9 & 7.0 & 6.0 & 6.0 & 6.8 & 6.9 & 0.0 & 0.1 & 0.1 & 0.1 \\
\hline Brit & 5.3 & 5.5 & 5.7 & 5.8 & 5.3 & 5.4 & 5.6 & 5.7 & 0.1 & 0.1 & 0.1 & 0.1 \\
\hline FBN & 4.5 & 4.6 & 5.0 & 5.1 & 4.4 & 4.5 & 4.8 & 5.0 & 0.1 & 0.2 & 0.2 & 0.2 \\
\hline Iber & 5.2 & 5.3 & 5.5 & 5.6 & 5.2 & 5.2 & 5.4 & 5.5 & 0.0 & 0.1 & 0.1 & 0.1 \\
\hline It & 5.6 & 5.7 & 5.9 & 6.0 & 5.5 & 5.6 & 5.8 & 5.9 & 0.1 & 0.1 & 0.1 & 0.1 \\
\hline Nord & 4.3 & 4.4 & 4.8 & 5.0 & 4.1 & 4.3 & 4.6 & 4.8 & 0.1 & 0.2 & 0.2 & 0.2 \\
\hline PICz & 4.2 & 4.5 & 5.0 & 5.2 & 3.9 & 4.3 & 4.8 & 5.0 & 0.3 & 0.2 & 0.2 & 0.2 \\
\hline SEast & 4.6 & 4.7 & 4.9 & 5.0 & 4.6 & 4.6 & 4.8 & 4.9 & 0.0 & 0.1 & 0.1 & 0.1 \\
\hline
\end{tabular}

Table 1: Electricity wholesale prices by 2020 in Eurocent per kWh.

By comparison of the price effects on the German market with those in other regions we find an almost identical picture on the closely linked marktets of Austria and Switzerland, due to an almost complete price convergence in 2020 across scenarios. Comparable effects can be found only on the Polish-Czech market, the nordic market and in the French-Dutch-Belgian region in scenarios of a low energy efficiency. Thereof, the price effect of the nuclear phase-out in 2020 may reach 0.3 Eurocent per $\mathrm{kWh}$ on the Polish-Czech market if emission trading is not ambitious. The electricity price effects on other European markets are with a maximum of 0.1 Eurocent per $\mathrm{kWh}$ almost negligible and can be attributed mainly to the nuclear policy induced increase of allowance prices in the ETS, which is reported in Table 2 .

Clearly, the allowance prices are higher if the targets for reductions are more restrictive. The model suggest very low prices under the current ETS reduction

\footnotetext{
${ }^{8}$ Results for the year 2030 are documented in the appendix.
} 


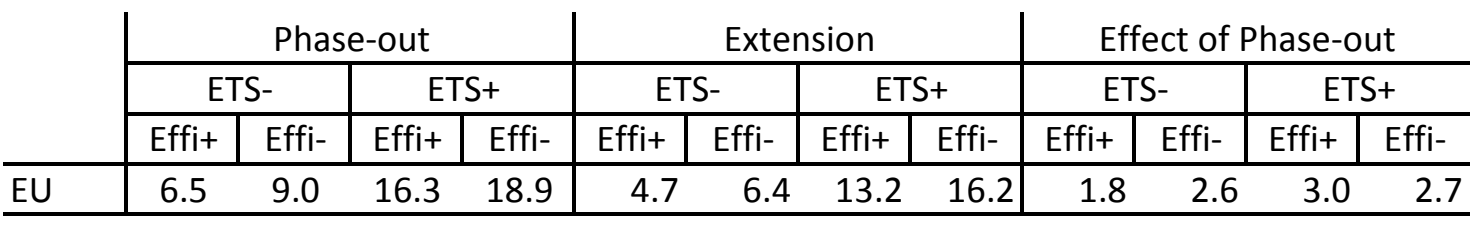

Table 2: European emission allowance prices by 2020 in Euro per ton of $\mathrm{CO}_{2}$.

legislation, resulting in prices below 10 Euro even if the German nuclear power plants are phased-out as projected and no significant reductions in energy efficiency are achieved. This means that the emission trading would probably see prices by 2020 which are well below allowance prices in 2011 and significantly lower than in the first five years of the emission trading system. Therefore, they provide only unreliable and insignificant signals for investments. A reduction of allowed emissions of 10 percent by 2020 would instead lead to prices between 13 and 19 Euro as can be seen from Table 2. The effects of the nuclear phase out range between 1.8 and 3.0 Euro per ton of $\mathrm{CO}_{2}$ and explain almost the complete price effect of countries that are not directly linked to the German electricity market. For instance, if a combined cycle gas fired power plant with emissions of $0.34 \mathrm{~kg} \mathrm{CO}_{2}$ per $\mathrm{kWh}$ is price setting for the relevant market, the price effect of an allowance price increase of 3.0 Euro per ton of $\mathrm{CO}_{2}$ would be 0.1 Eurocent per $\mathrm{kWh}$. This matches roughly the phase-out effect on prices in most loosely connected markets, and almost exactly matches the effects on the British aggregate.

Corresponding with the prices on the electricity and emission markets, the market driven investments are laid out in Table 3. Only comparatively low investments in addition to plants already under constuction are driven by the wholesale market projection. Particularly, no additional new capacities are built in the scenario of effective climate and energy savings policy by market incentives alone. Consequently, investments are not affected by the nuclear-phase out policy under these circumstances (Phase-out effect, Scenario ETS+ Effi+ in Table 3 ). However, such a development may not guarantee the reliability of the electricity system over a whole year and in all regions. For instance, in the Czech-Polish aggregate the installed firm capacity ${ }^{9}$ will slightly decrease in the decade up to 2020, while demand grows ceteris paribus by 20 percent. A similar picture evolves for the German firm capacity under the current phase-out policy if emission trading is ambitious and energy efficiency policy is successful. German firm capacity of the system parts referenced here ${ }^{10}$ decreases without additional investments by twenty percent.

However, in cases of a comparatively low energy efficiency we find significant additonal investments to be profitable on the German market. Under the current nuclear policy, $6 \mathrm{GW}$ additional new coal fired capacity is built in the scenario of a not ambitious ETS, while $4.1 \mathrm{GW}$ new combined cycle gas turbines are added if the

\footnotetext{
${ }^{9}$ Calculated with the following factors from installed net electric capacity: Lignite: 0.92, Hard Coal: 0.86, Gas: 0.84, Oil: 0.70, Nuclear: 0.83 Biomass: 0.65, Hydro run of river and lake: 0.40, Wind: 0.075 , Solar: 0.0 .

${ }^{10}$ Pump storage and measures that can substitute for firm power plants like demand side management would also have to be considered for a complete assesment of system reliability.
} 


\begin{tabular}{|c|c|c|c|c|c|c|c|c|c|c|c|c|c|}
\hline & \multicolumn{4}{|c|}{ Phase-out } & \multicolumn{4}{|c|}{ Extension } & \multicolumn{4}{|c|}{ Effect of Phase-out } \\
\hline & & \multicolumn{2}{|c|}{ ETS- } & \multicolumn{2}{|c|}{ ETS+ } & \multicolumn{2}{|c|}{ ETS- } & \multicolumn{2}{|c|}{ ETS+ } & \multicolumn{2}{|c|}{ ETS- } & \multicolumn{2}{|c|}{ ETS+ } \\
\hline & & Effi+ & Effi- & Effi+ & Effi- & Effi+ & Effi- & Effi+ & Effi- & Effi+ & Effi- & Effi+ & Effi- \\
\hline Gas & $\mathrm{De}$ & 0.0 & 0.0 & 0.0 & 4.1 & 0.0 & 0.0 & 0.0 & 0.0 & 0.0 & 0.0 & 0.0 & 4.1 \\
\hline Coal & $\mathrm{De}$ & 0.0 & 6.0 & 0.0 & 0.0 & 0.0 & 2.1 & 0.0 & 0.0 & 0.0 & 3.8 & 0.0 & 0.0 \\
\hline Gas & $\mathrm{Ch}$ & 0.0 & 0.0 & 0.0 & 0.4 & 0.0 & 0.0 & 0.0 & 0.0 & 0.0 & 0.0 & 0.0 & 0.4 \\
\hline \multirow{4}{*}{ Coal } & Bal & 0.4 & 0.4 & 0.0 & 0.0 & 0.4 & 0.4 & 0.0 & 0.0 & 0.0 & 0.0 & 0.0 & 0.0 \\
\hline & Brit & 1.2 & 0.0 & 0.0 & 0.0 & 2.2 & 0.0 & 0.0 & 0.0 & -1.0 & 0.0 & 0.0 & 0.0 \\
\hline & It & 4.3 & 0.0 & 0.0 & 0.0 & 4.3 & 4.3 & 0.0 & 0.0 & 0.0 & -4.3 & 0.0 & 0.0 \\
\hline & $\mathrm{PICZ}$ & 1.7 & 0.4 & 0.0 & 0.0 & 4.1 & 1.2 & 0.0 & 0.0 & -2.4 & -0.9 & 0.0 & 0.0 \\
\hline Gas & Total & 0.0 & 0.0 & 0.0 & 4.5 & 0.0 & 0.0 & 0.0 & 0.0 & 0.0 & 0.0 & 0.0 & 4.5 \\
\hline Coal & Total & 7.6 & 6.7 & 0.0 & 0.0 & 11.0 & 8.1 & 0.0 & 0.0 & -3.4 & -1.3 & 0.0 & 0.0 \\
\hline
\end{tabular}

Table 3: Investments in fossil fueled power plants in addition to the completion of plants under constuction by 2020 in GW net capacity.

ETS is tighter. Moreover, the major parts of these investments, i.e. $3.8 \mathrm{GW}$ coal and 4.1 GW gas fired capacities in the respective scenarios, are due to the the phase-out. In the other regions of Europe the phase-out effects on investments are negative in case of a strict ETS since the profitability of coal fired power plant projects in Italy, the British aggregate and the Czech-Polish aggregate are negatively influenced by the mixture of higher electricity prices and higher emission prices. To the contrary, investment in gas fired power units in other markets are not decreased by the nuclear phase-out in Germany.

European investments are reported as the sum over all countries at the bottom of the table. Overall, we find only coal investments in scenarios with the current ETS-setting, and only gas investments in scenarios with more ambitious ETS-policy. Thus, the emission price increase of about ten Euro per ton $\mathrm{CO}_{2}$ between these ETSpolcies induces a complete shift between coal and gas investments, although variable costs of coal production are smaller than those of gas fired production in 2020 up to a emission price of about 60 Euro. The high sensitivity of investments with regard to emission prices can be explained by higher investment costs of coal fired units in combination with the low utilization rates of new installed plants reported in Table 4 below.

In particular, the German utilization rates are expected to be low, mainly due to the pronounced increase of low variable costs of renewables. We find that utilization of new hard coal plants in 2020 will not exceed 62 percent utilization even in the most favorable scenario for coal, i.e. ETS- Eff- and a accelerated nuclear phaseout. Under current nuclear policy and a tight ETS regime, new coal fired plants in Germany are utilized only between 40 and 46 percent. If the lifetime extension of nuclear power plants would have been carried out, the utilization of hard coal in a tight ETS regime would have been only between 30 and 40 percent. Similarly, the utilization rates of German gas combined cycle units in 2020 are low with at most 


\begin{tabular}{|c|c|c|c|c|c|c|c|c|c|c|c|c|c|}
\hline & \multicolumn{4}{|c|}{ Phase-out } & \multicolumn{4}{|c|}{ Extension } & \multicolumn{4}{|c|}{ Effect of Phase-out } \\
\hline & & \multicolumn{2}{|c|}{ ETS- } & \multicolumn{2}{|c|}{ ETS+ } & \multicolumn{2}{|c|}{ ETS- } & \multicolumn{2}{|c|}{ ETS+ } & \multicolumn{2}{|c|}{ ETS- } & \multicolumn{2}{|c|}{ ETS+ } \\
\hline & & Effi+ & Effi- & Effi+ & Effi- & Effi+ & Effi- & Effi+ & Effi- & Effi+ & Effi- & Effit & Effi- \\
\hline Gas & De & 18 & 19 & 19 & 31 & 10 & 18 & 11 & 20 & 8 & 11 & 80 & 58 \\
\hline Coal & De & 52 & 62 & 41 & 45 & 42 & 51 & 31 & 40 & 24 & 22 & 31 & 14 \\
\hline Gas & $\mathrm{Ch}$ & 26 & 23 & 28 & 36 & 24 & 25 & 22 & 32 & 6 & -5 & 29 & 11 \\
\hline \multirow{4}{*}{ Coal } & Bal & 100 & 100 & 0 & 0 & 100 & 100 & 100 & 0 & 0 & 0 & -100 & 0 \\
\hline & Brit & 100 & 100 & 99 & 98 & 100 & 100 & 100 & 99 & 0 & 0 & -1 & -1 \\
\hline & It & 100 & 100 & 100 & 100 & 100 & 100 & 100 & 100 & 0 & 0 & 0 & 0 \\
\hline & $\mathrm{PICZ}$ & 80 & 80 & 75 & 72 & 75 & 81 & 78 & 75 & 6 & 0 & -4 & -4 \\
\hline
\end{tabular}

Table 4: Utilization rates of new installed coal and combined cycle gas fired power plants in 2020 in percent of full utilization and effect of phase-out relative to extension in percent.

31 percent, reached under low energy efficiency and an ambitious ETS regime at current nuclear policy.

With a focus on those utilization rates at which investment actually takes place and at which the phase-out affects investments, Table 4 highlights these cases in bold. For Germany, we find that only in cases of highest utilization rates investment is induced. Moreover, the phase out effect on the utilization of new plants relative to utilization in the extension case is 22 percent for hard coal, while it is 58 percent for gas combined cycle units. Consequently, the comparative advantage of gas fired power plants against coal fired power plants not only increases due to higher emission prices but also due to a relatively high increase in utilization. By and large this picture also holds for the other European countries. The relative utilization rates of coal fired power plants decrease or at most increase by six percent, while utilization of gas units increases by up to 29 percent.

Increasing electricity prices in Germany imply that in total, increasing utilization, additional investments and increased German net electricity imports do not completely compensate the reductions of supply in nuclear energy. The physical electricity trade balance of the modeled regions in the different scenarios in 2020 is laid out in Table 5 and shows that a negative physical trade balance in Germany would arraise in all scenarios regardless of the nuclear phase-out plannings. Moreover, the effects of the phase-out are at most a reduction of the physical trade balance of about 7.5 TWh in the cases of a successful energy efficiency policy. If efficiency policy is less effective, the trade effects are smaller. This has to be explained by the increased investments in low efficiency scenarios, which partially reduce the need for higher imports. Across all scenarios, however, those additional imports are mainly sourced by the Nordic countries, Austria and Switzerland, which can be seen from according columns of the right hand side of the Table 5. 


\begin{tabular}{|c|c|c|c|c|c|c|c|c|c|c|c|c|}
\hline & \multicolumn{4}{|c|}{ Phase-out } & \multicolumn{4}{|c|}{ Extension } & \multicolumn{4}{|c|}{ Effect of Phase-out } \\
\hline & \multicolumn{2}{|c|}{ ETS- } & \multicolumn{2}{|c|}{ ETS+ } & \multicolumn{2}{|c|}{ ETS- } & \multicolumn{2}{|c|}{ ETS+ } & \multicolumn{2}{|c|}{ ETS- } & \multicolumn{2}{|c|}{ ETS+ } \\
\hline & Effi+ & Effi- & Effi+ & Effi- & Effi+ & Effi- & Effi+ & Effi- & Effi+ & Effi- & Effi+ & Effi- \\
\hline $\mathrm{De}$ & -23.6 & -24.5 & -26.2 & -33.5 & -16.0 & -22.4 & -18.8 & -27.3 & -7.5 & -2.1 & -7.4 & -6.2 \\
\hline At & 6.8 & 6.7 & 7.8 & 10.7 & 3.6 & 6.3 & 3.8 & 8.2 & 3.2 & 0.5 & 4.0 & 2.5 \\
\hline $\mathrm{CH}$ & 3.3 & 3.8 & 4.8 & 7.4 & 1.5 & 3.1 & 2.9 & 5.1 & 1.8 & 0.7 & 1.9 & 2.3 \\
\hline Bal & 0.0 & 0.0 & 0.0 & 0.0 & 0.0 & 0.0 & 0.0 & 0.0 & 0.0 & 0.0 & 0.0 & 0.0 \\
\hline Brit & -10.3 & -10.1 & -10.3 & -10.2 & -10.2 & -10.3 & -10.3 & -10.3 & -0.1 & 0.2 & 0.0 & 0.1 \\
\hline FBN & 30.2 & 30.1 & 29.4 & 28.6 & 30.4 & 30.3 & 29.9 & 29.4 & -0.2 & -0.2 & -0.6 & -0.9 \\
\hline Iber & -4.8 & -4.6 & -3.9 & -3.2 & -5.0 & -4.8 & -4.4 & -4.0 & 0.2 & 0.2 & 0.5 & 0.7 \\
\hline It & -15.2 & -15.4 & -15.2 & -15.1 & -15.2 & -15.2 & -15.3 & -15.2 & 0.0 & -0.2 & 0.1 & 0.1 \\
\hline Nord & 13.3 & 14.9 & 15.2 & 17.6 & 9.9 & 13.2 & 13.5 & 15.7 & 3.4 & 1.7 & 1.7 & 1.9 \\
\hline $\mathrm{PICz}$ & 0.2 & -1.0 & -1.6 & -2.1 & 1.1 & -0.2 & -1.3 & -1.6 & -0.8 & -0.8 & -0.3 & -0.5 \\
\hline SEast & 0.0 & 0.0 & 0.0 & 0.0 & 0.0 & 0.0 & 0.0 & 0.0 & 0.0 & 0.0 & 0.0 & 0.0 \\
\hline
\end{tabular}

Table 5: Physical trade balances and effect of the phase-out in Terawatthours.

\section{Summary and Conclusion}

We develop a long term oligopolistic electricity market model with investment, hourly load profile, power plant ramp-up and emission trading, which is then applied to the European electricity market to study the case of the German accelerated nuclear phase-out. We focus on phase-out impacts on electricity prices, emission prices and power plant investment and utilization. It turns out that the effects depend crucially on the success of two other important policies, i.e. the achievement of the German energy efficiency goals in the electricity sector and the evolution of the European emission trading system.

Due to the acceleration of nuclear phase-out, we find an increase of wholesale electricity prices in Germany of at most ten percent and of about six percent if the European emission trading system and the German energy efficiency policy are comparatively ineffective. These price effects translate almost identically to Austria and Switzerland, since these markets are particularly well connected in relation to their size. On other markets, the price impacts of the phase-out are of far minor size and may reach at most about fifty percent of the effect in Germany.

A major transmission channel of the price effects is the market for emissions which induces price effects even in markets that are physically not significantly connected with the German market. We find emission price increases of between 1.8 and 2.6 Euro per ton $\mathrm{CO}_{2}$ under the current ETS policy regime and higher effects if the emission trading is tightened to provide a significant signal for investments. If the current ETS-policy is assumed to continue, the model computes allowance prices of below ten Euro and a price of 6.5 Euro per ton if the German energy savings policy is successful. These modest prices can be explained on one hand by the accelerated use of renewable energies in combination with a dampened electricity demand, and, on the other hand, an unambitious ETS allowance reduction schedule.

Another insight is gained with regard to investment prospects. Our modeling 
exercise shows generally low investment into additional gas or hard coal fired power plants. Only in cases of limited success of energy efficiency policy, significant investments are likely to be attractive in the upcoming decade. Under these conditions, 6 gigawatt additional hard coal fired power plants are profitable under the current ETS regime, and 4.1 gigawatt natural gas fired power plants under a slightly more ambitious ETS regime. The major part of these investments are induced by the accelerated phase-out. However, these market based investments are not necessarily sufficient to guarantee a secure supply in Germany since firm capacity significantly decreases by 2020 .

Our results show also that an increase of emission allowance prices to about twenty Euro per ton is likely to trigger a complete shift from hard coal to natural gas as fuel carrier for new investments. At first glance this seems to be a rather low emission price for the shift between these fossil fuels, since in 2020 variable costs including emission allowance costs of natural gas need an allowance price of at least sixty Euro to break even with hard coal. However, decreasing utilization rates due to increased use of renewable energies lead to a growing importance of capital cost, which are comparably modest for gas fired power plants. In addition, the nuclear phase-out seems advantageous in particular for natural gas not only due to higher emission prices, but also due to a relatively pronounced increase of utilization compared to coal fired units.

\section{References}

[1] Bushnell, J.B., Mansur, E.T. and C. Saravia (2008), "Vertical Arrangements, Market Structure, and Competition: An Analysis of Restructured US Electricity Markets", American Economic Review, Vol 98, No 1, pp. 237-266.

[2] Fürsch, M., Lindenberger, D.,Malischek, R.,Nagl, S., Panke, T., and J. Trüby (2012), "German nuclear policy reconsidered: Implications for the electricity market", EWI Working Paper, No. 11/12.

[3] Green, R.J., and D.M. Newbery (1992), "Competition in the British Electricity Spot Market", Journal of Political Economy, 100(5), pp. 929-953.

[4] Matthes, F. C, Harthan, R.O., and C. Loreck (2011a). "Schneller Ausstieg aus der Kernenergie in Deutschland. Kurzfristige Ersatzoptionen, Strom- und $\mathrm{CO}_{2}$-Preiseffekte", Kurzanalyse fr die Umweltstiftung WWF Deutschland, Ökoinstitut, Berlin.

[5] Matthes, F. C, Harthan, R.O., and C. Loreck (2011b). "Atomstrom aus Frankreich? Kurzfristige Abschaltungen deutscher Kernkraftwerke und die Entwicklung des Strom-Austauschs mit dem Ausland", Kurzanalyse fr die Umweltstiftung WWF Deutschland, Ökoinstitut, Berlin.

[6] Müsgens, F. (2006). "Quantifying Market Power in the German Wholesale Market Using a Dynamic Mulity-Regional Dispatch Model", The Journal of Industrial Economics, LIV (4): 471-498. 
[7] Murphy, F. H., and Y. Smeers (2005), "Generation capacity expansion in imperfectly competi- tive restructured electricity markets", Operations Research, 53(4), pp. 646-661.

[8] Neuhoff, K., J. Barquin, M.G. Boots, A. Ehrenmann, B.F. Hobbs, and F.A.M. Rijkers (2005), "Network-Constrained Models of Liberalized Electricity Markets: The Devil is in the Details", Energy Economics, 27(3), pp. 495525 .

[9] Kunz, F., Hirschausen, C., Möst, D., and H. Weigt (2011), "Nachfragesicherung und Lastflüsse nach dem Abschalten von Kernkraftwerken in Deutschland Sind Engpässe zu befürchten?", Electricity Markets Working Papers TU Dresden, WP-EM-44.

[10] Traber, T., and C. Kemfert (2009), "Impacts of the German Support for Renewable Energy on Electricity Prices, Emissions, and Firms", The Energy Journal, Vol 30, No 3, pp. 155-178.

[11] Traber, T., and C. Kemfert (2011), "Gone with the Wind? - Electricity Market Prices and Incentives to Invest in Thermal Power Plants under Increasing Wind Energy Supply", Energy Economics, Vol 33, pp. 249-256. 


\section{Notation}

\begin{tabular}{|c|c|}
\hline$I$ & Set of firms, where $i$ denotes a single firm \\
\hline$Y$ & Set of time periods, where $y$ denotes a single period, i.e. $2010,2020,2030$ \\
\hline$T$ & Set of time steps, where $t$ denotes a single time step, i.e. $\mathrm{t}=1 . .48$ \\
\hline$N$ & Set of technologies \\
\hline$S$ & Set of regions, where $s$ denotes a single region \\
\hline$q^{i, y, t, n}$ & $\begin{array}{l}\text { Electricity production of firm } i \text { in period } y \\
\text { and time step } t \text { and technology } n\end{array}$ \\
\hline$r^{i, y, t, n}$ & $\begin{array}{l}\text { Ramp-up of of firm } i \text { in period } y \text { for additional generation } \\
\text { in time step } t \text { and technology } n\end{array}$ \\
\hline$k^{i, y, n}$ & Power plant investment of firm $i$ in period $y$ in technology $n$ \\
\hline$P^{y, t, s}\left(X^{y, t, s}\right)$ & Inverse demand in period $y$, time step $t$, and region $s$ \\
\hline$C_{q}^{n}$ & Generation costs of technology $n$ \\
\hline$C_{r}^{n}$ & Costs of ramp-up of technology $n$ \\
\hline$F^{n}$ & Investment costs of technology $n$ \\
\hline$\delta$ & discount rate \\
\hline$\kappa^{i, y, t, n}$ & $\begin{array}{l}\text { Shadow price of capacity of firm } i \text { in period } y \text {, } \\
\text { time step } t \text { and technology } n\end{array}$ \\
\hline$\rho^{i, y, t, n}$ & Shadow price of capacity restriction of installed \\
\hline$\psi^{i, y, t, n}$ & Shadow price of capacity restriction of installed \\
\hline$\iota^{i, y, n}$ & Shadow price of capacity restriction of installed \\
\hline$\sigma^{y}$ & Price of carbon emissions in period $y$ \\
\hline$X^{y, t, y}$ & Total electricity supply in region $s$ time step $t$ and period $y$ \\
\hline$E^{y}$ & Total emissions of the electricity sector in period $y$ \\
\hline$E x^{y, s, s s}$ & Export from region $s$ to $s s$ \\
\hline$E\left(q^{i, t}\right)$ & $\begin{array}{l}\text { Emissions of electricity production of firm } i \\
\text { in period } t \text { in installed power plants }\end{array}$ \\
\hline$\kappa^{i, r, t}$ & $\begin{array}{l}\text { Shadow price of capacity restriction of installed } \\
\text { power plants of firm } i \text { in region } r \text { and period } t\end{array}$ \\
\hline$\phi^{i, t, n}$ & $\begin{array}{l}\text { Shadow price of capacity expansion restriction of firm } i \\
\text { in period } t \text { and technology } n\end{array}$ \\
\hline$\tau^{r, r^{*}, t}$ & Shadow price of transmission capacity from region $r$ to $r^{*}$ in period $t$ \\
\hline$\epsilon^{r, t}$ & price elasticity of residual demand in region $r$ in period $t$ \\
\hline$\vartheta^{i, r, t}$ & market share of firm $i$ in the strategic segment of region $r$ in period $t$ \\
\hline
\end{tabular}

